\title{
Relações internas e conversa estratégica nas pequenas e médias empresas
}

\section{(Internal relationships and strategic conversation in small and medium enterprises)}

\author{
Edmilson Lima, Ph.D. \\ edmilsonolima@gmail.com \\ Professor do Programa de Pós-Graduação em Administração Universidade Nove de Julho \\ Editor Científico Responsável: Prof. Dr. Bezamat de Souza Neto \\ Professor do Departamento de Ciências Administrativas e Contábeis da Universidade Federal de São João Del Rei
}

Recebido em: 17/09/08

Aprovado em: 23/04/09

\begin{abstract}
Resumo
Neste estudo empírico e qualitativo, ao se tratarem as relações na pequena e média empresa (PME), enfoca-se a centralidade dos proprietários-dirigentes dessa organização assim como a interação deles entre si e com os demais membros da PME. A centralidade e as relações internas (dentro da PME) desses importantes atores têm impacto direto sobre sua gestão estratégica, mas continuam recebendo pouca atenção dos pesquisadores em Administração. Dentre os resultados deste estudo, a conversa estratégica aparece como um processo essencial de manifestação das relações dos proprietários-dirigentes para realizarem a gestão estratégica. Por meio dela, eles forjam os itens de orientação estratégica (missão, visão e objetivos) e estabelecem o sentido para a cooperação entre as pessoas na empresa. Ao final do artigo, são apresentadas sugestões para a melhoria das práticas estratégicas nas PME e para futuras pesquisas.
\end{abstract}

Palavras-chave: Pequenas e médias empresas. Gestão estratégica. Relações. Conversa estratégica.

\begin{abstract}
This empirical and qualitative study approaches relationships in the small and medium enterprise (SME), paying special attention to the centrality of their owner-managers and the relationships among them and with the other members in the SME. The centrality and the internal relationships (inside the SME) of these important actors have a direct impact on the strategic management of SME, but this theme receives little attention in management studies. Among the results of our research, the strategic conversation appears as an essential process of manifestation of the owner-managers' relationships to do the strategic management. Through this process, they conceive the strategic orientation elements (mission, vision and objectives) and establish the direction to the cooperation of people in the organization. The conclusion of this article presents some suggestions to the strategic practice and future researches.
\end{abstract}

Key word: SME. strategic management. relationships. strategic conversation. 


\section{INTRODUÇÃO}

Quando se trata do fator humano e seus reflexos sobre a gestão estratégica das PME, há diferentes questões que já receberam tratamento dos estudiosos da Administração, entre elas a alta restrição do pessoal em termos de disponibilidade e qualificação; a fraca fixação do pessoal, principalmente dos mais experientes ou qualificados devido a limitações financeiras; a dificuldade de contratação, dada a média salarial mais baixa nas PME. Muitos estudiosos interessaram-se exatamente pelas formas possíveis de superação dessas dificuldades típicas dos pequenos negócios.

Contudo dois temas óbvios e de grande relevância, apesar de não passarem desapercebidos aos olhos de muitos, apenas agora começam a receber a atenção dos pesquisadores brasileiros. Trata-se da preponderância dos dirigentes em meio aos membros de sua PME assim como das relações deles entre si e com esses membros (relações internas, ou seja, dentro da organização) como importantes fatores de influência da gestão estratégica.

O presente artigo tem por objetivo tratar desses temas. Ele é fruto de uma pesquisa empírica com o interesse de investigar as atividades dos dirigentes e suas relações nos processos estratégicos das PME. Diferentes resultados dessa pesquisa são aqui apresentados e discutidos. Contudo, antes disto, as seções a seguir apresentam uma revisão de literatura e os métodos de pesquisa utilizados. A seção final, de conclusão, dá fechamento às principais questões tratadas no artigo e traz sugestões para a prática em PME e para futuras pesquisas.

\section{PANORAMA DAS RELAÇÕES INTERNAS NAS PME}

Os dirigentes são atores centrais na definiçãa das características da PME. Segundo Hafsi (1985), esse elo tende a não ser tão estreito nas grandes empresas. Para ele, o dirigente da PME é um "administrador direto", pois ele tem "um conhecimento direto e íntimo da situação [de gestão]. Ele pode então enfrentar a incerteza e a ambiguidade utilizando sua experiência e sua intuição" (HAFSI, 1985, p. 6). Isto não é comum nas grandes organizações, em que a divisão do trabalho é geralmente maior. Como diz Filion (1988), o dirigente é um ator preponderante na PME, que se desenvolve à sua imagem.

Segundo Jennings e Graham (1997), a estrutura das organizações de pequeno tamanho 
se desenvolve em torno dos interesses e das habilidades de seus principais atores, os proprietários-dirigentes. De acordo com os mesmos autores, o processo administrativo das PME é diferente do que se vê nas grandes empresas devido à motivação dos dirigentes. Nessas últimas, os objetivos geralmente são financeiros e o sucesso é obtido pela maximização dos lucros, e, nas PME, a busca do sucesso financeiro não costuma ser mais importante do que o desejo de independência, de realização e de ter responsabilidades. Assim, a compreensão do processo de gestão nas PME não pode ser buscada sem se compreender a maneira de ser, as aspirações e as experiências desses principais atores da gestão.

A partir dessas considerações e de uma perspectiva sistêmica, pode-se utilizar o Esquema 1 (LIMA, 2002) para representar a dinâmica de interação dos membros da PME com os dirigentes. O formato radial do modelo representa visualmente a irradiação das influências internas provenientes principalmente dos dirigentes, influências que definem em grande parte a forma e o conteúdo do processo de aprendizagem da coletividade dos membros da PME quanto às atividades da empresa. O modelo é útil para se entender a formação dos itens de orientação estratégica (visão, missão e objetivos), assim como das estratégias, conhecimentos e entendimentos compartilhados, elementos que se constroem, em grande parte, pela aprendizagem dos atores da organização e pelas relações deles entre si.

No modelo, cujo núcleo corresponde aos dirigentes, um nível sistêmico interage com os outros de modo direto - o que é representado pelas flechas - ou de modo indireto, pela mediação de outro nível. Por exemplo, no compartilhamento da visão (imagem mental de um futuro desejado a realizar) de um dirigente, seu nível sistêmico individual interage direta e indiretamente com o nível da coletividade de toda organização. A interação direta pela comunicação é representada pela flecha que liga os dois níveis enquanto a interação indireta é a que ocorre por intermédio da equipe de direção. 


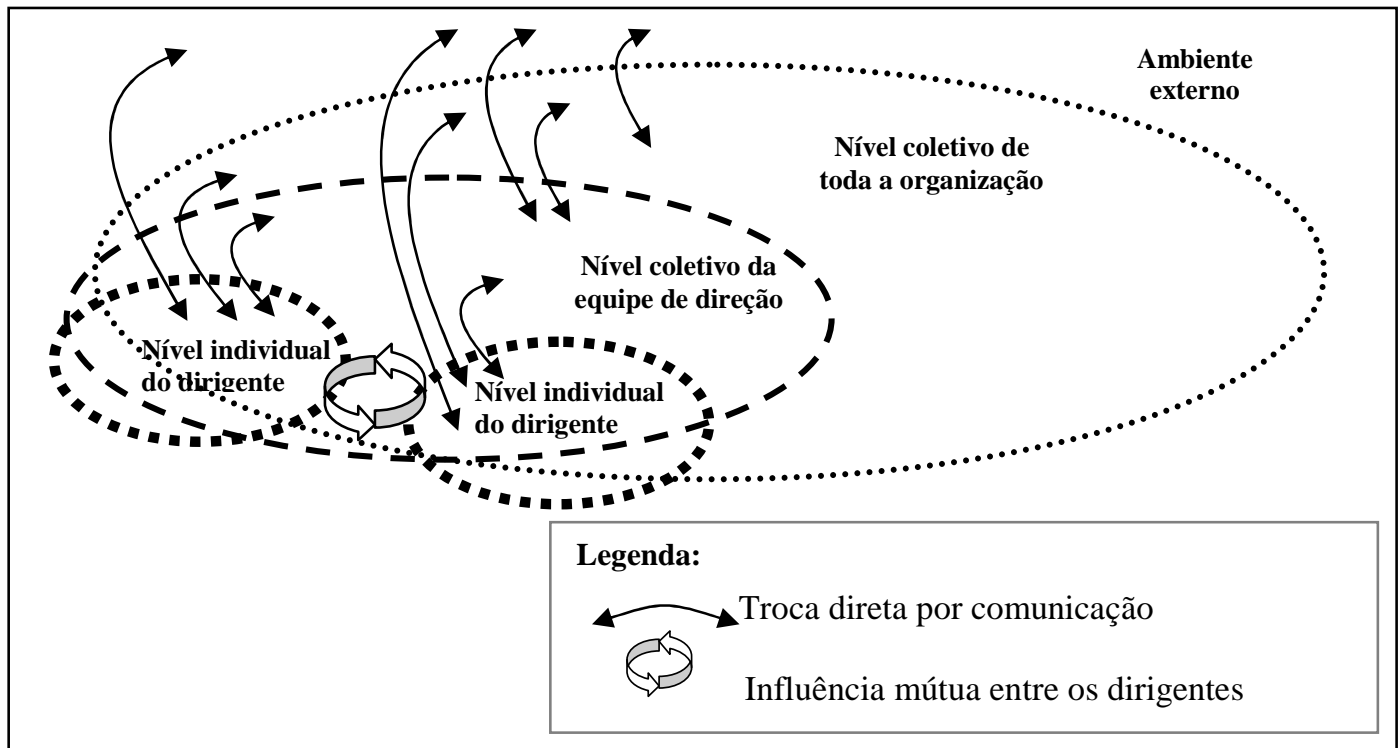

Figura 1: Esquema 1 - Modelo das relações entre níveis sistêmicos na PME Fonte: Adaptado de LIMA, 2002.

Uma versão preliminar desse modelo poderia apresentar os níveis sistêmicos dos dirigentes e de sua equipe de direção completamente inseridos no interior das fronteiras que limitam o nível sistêmico de toda PME. Contudo, na realidade, o nível sistêmico do dirigente e o da equipe de direção não são completamente internos ao sistema PME, visto que várias de suas dimensões não estão vinculadas à esfera organizacional e do trabalho - o que não significa, evidentemente, que não possam influenciar essa esfera. Por exemplo, as questões familiares fazem parte da vida pessoal e privada dos membros da PME, não estando inseridas dentro desse sistema, mas podendo influenciá-lo, como se vê quando um deles atravessa uma fase de dificuldades em sua família, e isso repercute em seu trabalho. Para respeitar essa realidade, o modelo do Esquema 1 apresenta uma porção dos níveis sistêmicos do dirigente e da equipe de direção fora da representação do nível coletivo de toda a PME.

O Esquema 1, que os estudos empíricos de Lima (2004) e Lima e Zoschke (2007) ajudam a corroborar, inclui a noção de irradiação de elementos de aprendizagem entre os diferentes níveis de subjetividade na PME, o que ocorre principalmente por meio dos dirigentes, que são importantes transferidores de sentido (sensegivers, segundo GIOIA e CHITTIPEDDI, 1991). Esses atores organizacionais modelam a PME e a subjetividade de seus membros à sua imagem, em grande parte segundo o que eles já aprenderam e segundo o que aprendem em suas vidas pessoal e de trabalho - suas imagens, sua visão, seu saber-ser (savoir-être), seu saber-fazer (know-how), seu saber-tornar-se (savoir-devenir) e seus conhecimentos (FILION, 1988, 1990). As imagens são articulações da subjetividade de uma pessoa que estabelecem sua maneira de perceber e de compreender a realidade; essas imagens 
incluem o humor da pessoa, suas atitudes e suas intenções subjacentes ao processo de percepção, elementos que podem forjar sua maneira de pensar assim como suas tomadas de iniciativa e de decisão (FILION, 1988, 1990).

Nas relações entre os membros de uma organização, a comunicação é fundamental para a troca de informações e para a coordenação das atividades (BARNARD, 1938), para o estabelecimento das orientações estratégicas, dentre as quais a visão (LIMA 2004, 2007), e para a aprendizagem deles entre si (LUNDBERG, 1995; TOMPKINS, 1995). Por exemplo, a formulação de estratégias pode ser vista como um processo de aprendizagem. Assim, ela se baseia em atividades de desenvolvimento de conhecimentos e na troca, interpretação e retenção de informações (HUBER, 1991), processos que são todos baseados na comunicação (GIROUX; TAYLOR, 1995).

Quando se trata do desenvolvimento da visão a guiar os rumos da organização, segundo Robbins e Duncan (1988), os dirigentes formam sua interpretação da realidade ouvindo e interagindo com as pessoas que os cercam; a partir daí, eles formam sua visão individual e a compartilham, pela comunicação, com outros membros da equipe de direção e da organização obtendo o compromisso coletivo para realizá-la.

Dada a sua preponderância, os dirigentes são os principais agentes influenciadores da mente organizacional (MITROFF, 1983) na PME. O agente influenciador, na perspectiva de Mitroff (1983), é uma pessoa ou entidade qualquer que exerce influência sobre a subjetividade dos atores organizacionais, em que se encontram muitos dos fundamentos de suas decisões e ações relativas à organização.

\subsection{As PME e seus membros como sistemas que aprendem}

Os sistemas humanos e sociais tendem a mudar sua lógica interna de comportamento a fim de manter relações com seu contexto que sejam favoráveis a sua existência e a seu desenvolvimento. Isto significa que tais sistemas apresentam a propriedade de aprendizagem, seja ela muito ou pouco desenvolvida, consciente ou não. Há um consenso entre os teóricos da Administração, segundo o qual é fundamental que uma organização apresente compatibilidade entre sua condição interna e seu contexto para continuar a existir e para poder se desenvolver no longo prazo. A manutenção dessa compatibilidade depende essencialmente da capacidade de aprendizagem organizacional gerada pelos membros da organização (FIOL; 
LYLES, 1985).

Para Argyris e Schön (1978), a aprendizagem organizacional ocorre quando os membros respondem às mudanças dos meios interno e externo de sua organização, alterando sua lógica de ação em vigor para corrigir diferenças reais ou previstas (“erros”) entre os resultados obtidos com suas atividades e os resultados que desejam obter. Já segundo Huber (1991, p. 89), "uma entidade aprende se, por meio do processamento de informações, seus comportamentos potenciais são mudados".

A aprendizagem organizacional não é simplesmente a soma das aprendizagens individuais dos membros de uma organização. Ela tampouco emerge de uma só pessoa, mas sim da interação e da combinação de capacidades e conhecimentos de diferentes membros da mesma organização (FIOL, 1994; LUNDBERG, 1995). Ela ocorre, portanto, pelo compartilhamento de elementos da aprendizagem entre indivíduos em interação numa organização (KIM, 1993), compartilhamento realizado pela difusão de diferentes indivíduos, e de "conteúdos" da aprendizagem, como os conhecimentos, as competências, as aspirações, etc.

Assim, pode-se dizer que a aprendizagem organizacional só terá ocorrido caso uma coletividade de membros de uma organização apresente competências, conhecimentos ou demais "conteúdos" de aprendizagem, independentemente de todo e qualquer membro que contribuiu ao processo com os resultados de sua aprendizagem individual difundidos a outros (TOMPKINS, 1995). Cada indivíduo ou grupo de indivíduos pode aprender assimilando elementos de competência, de conhecimento ou dos demais "conteúdos" de aprendizagem que são difundidos por outros (resultantes da aprendizagem destes), além de poder fazê-lo com base em seu próprio processo de aprendizagem individual. Ou seja, um indivíduo ou grupo aprende de forma independente e também a partir do aprendizado realizado e difundido por outros. A aprendizagem de um indivíduo que se beneficia da aprendizagem de outros é, portanto, implícita à aprendizagem organizacional, que ocorre graças à difusão, entre diferentes indivíduos, de "conteúdos" de aprendizagem por eles gerados (BEEBY; BOOTH, 2000) - e a comunicação interpessoal é o principal meio para essa difusão (LUNDBERG, 1995).

Nessa perspectiva, a organização é um campo de difusão de elementos de aprendizagem no qual cada membro tende a contribuir à aprendizagem e a aprender dos outros por meio da comunicação em suas relações. Essa noção é convergente com o modelo das relações entre níveis sistêmicos na PME (Esquema 1), cuja representação visual facilita o entendimento das PME como um campo de difusão de elementos de aprendizagem no qual os 


\section{MÉTODOS DE PESQUISA}

Os métodos visaram essencialmente à descrição e à compreensão dos processos que compunham o fenômeno estudado segundo sua sequência temporal e sua integração com o contexto. O método de estudo multicaso (EISENHARDT, 1989) mostrou-se apropriado. Ele foi empregado segundo uma abordagem qualitativa, que é de fundamental importância para que se leve em consideração o contexto do fenômeno estudado (PETTIGREW, 1992). A pesquisa foi exploratória, dada a novidade dos temas abordados.

A amostra de PME estudadas foi composta de seis empresas. Duas delas são canadenses e as outras quatro são brasileiras. Quanto a suas atividades, duas são de biotecnologia, uma é produtora de software e três são confecções.

As PME da amostra foram escolhidas devido a seu alto grau de correspondência com os seguintes critérios de seleção: 1) ter as características qualitativas de uma PME, apresentando propriedade e administração independentes de qualquer outra empresa, administração personalizada (refletindo a figura de seus proprietários) e uma pequena fatia de mercado; 2) respeitar os critérios quantitativos IBGE/SEBRAE de até 499 empregados na indústria ou até 99 no comércio ou serviços; 3) ser ou ter sido dirigida por uma equipe de direção; 4) possibilitar entrevistas com, ao menos, um fundador que informe sobre fatos ocorridos desde a fundação; 5) ter ou ter tido, ao menos, três anos de existência, além de contribuir para a diversidade de dados colhidos com variações em suas equipes de direção, localização geográfica e setor de atividade.

$\mathrm{O}$ enfoque metodológico utilizado baseou-se principalmente nas propostas de Eisenhardt (1989). As contribuições dessa autora são orientadas à construção de teoria descritiva do fenômeno estudado a partir do estudo qualitativo multicaso (replicative case research). Foi feita a análise em profundidade dos dados obtidos relativos a cada caso de empresa (análise intrassítio) e a análise comparativa (análise intersítio) entre os casos (MILES; HUBERMAN, 1994).

Várias fontes de dados relativas aos seis casos foram exploradas: textos disponíveis (jornal de comunicação com distribuidores, artigos de jornais e revistas e textos disponíveis na internet), fotos disponíveis (em alguns casos), observações e, principalmente, entrevistas 
em profundidade. Estas foram realizadas com informantes-chave de cada PME, dentre os quais os dirigentes considerados os mais importantes para interrogar. As entrevistas foram realizadas segundo um roteiro semiestruturado e flexível que, se necessário, poderia ser adaptado, ampliado ou simplificado durante a coleta de dados em cada PME. Com duração média de 3,5 horas, as entrevistas foram gravadas em fitas cassete.

Neste estudo, as citações de entrevistas contarão com a identificação de seus autores e das empresas a que estão vinculados apenas na situação em que isto foi expressamente autorizado por eles.

\subsection{Resultados relativos às relações internas e à preponderância dos dirigentes}

Os resultados aqui apresentados se mostraram estáveis apesar das variações de tipo das PME, sua localização ou condição de seus membros. Em outras palavras, eles se aplicam igualmente a todas as empresas da amostra, independentemente das diferenças entre elas quanto a esses quesitos.

No que diz respeito à preponderância dos dirigentes em meio aos membros de sua PME assim como às relações deles entre si e com as demais pessoas de sua empresa, no estudo corrobora-se o Esquema 1 (modelo das relações entre níveis sistêmicos na PME). Isso reforça sua validade, já anteriormente fortalecida pelos estudos de Lima (2004) e Lima e Zoschke (2007).

Em todas as PME da amostra, a prática da "simulação coletiva" é um ponto comum não apenas para resolver questões de gestão estratégica, mas também questões das mais variadas - envolvendo duas ou mais pessoas em intensa interação. A simulação coletiva é um modo de aprendizagem coletiva antecipada a respeito de uma situação-problema qualquer que duas pessoas ou mais se interessam em resolver. Trata-se de um processo em que mais de uma pessoa se põe a imaginar de modo proativo como proceder para chegar a resultados satisfatórios na solução de uma situação-problema, como ilustra o exemplo a seguir.

Frequentemente, empregados do nível hierárquico mais baixo em pequenas empresas levam a seus diretores sugestões de novos produtos para lançar no mercado. Desafiando uma possível crença no isolamento dos dirigentes das PME na geração de ideias estratégicas, de marketing e para seu trabalho em geral, esta prática é corrente em 

regiões como a do polo confeccionista de roupa íntima de Nova Friburgo - RJ (onde se localiza uma das PME estudadas). Nessa cidade, não é raro que costureiras (ou mesmo costureiros) recebam uma gratificação quando levam a seus empregadores boas ideias de novos produtos. Tais ideias, muitas vezes, vêm de novidades que as costureiras encontram em lojas de roupa da região. Ao levar a ideia para seu empregador, a costureira normalmente entra em um diálogo com ele sobre como utilizar a ideia obtida, imaginando com ele, e até com mais pessoas, como uma costura ou outra pode ser feita, como uma peça comprada pode ser desmontada para se fazer "engenharia reversa" (mesmo que esta expressão não seja usada por eles), etc. Nesse processo, que pode durar dias ou até meses, diferentes informações são usadas e questões das mais variadas são pensadas, inclusive o gosto do consumidor, imaginando-se coletivamente o uso de diferentes possibilidades de solução para uma situação-problema cuja forma se precisa ao longo do processo nas mentes de diferentes pessoas. A situação-problema, neste exemplo, é decidir se um novo produto será lançado e como ele poderia ser feito e colocado no mercado. A pessoa que levou inicialmente a sugestão, provocando a simulação coletiva, pode participar apenas de uma etapa dessa simulação ou até de todas.

Quadro 1: Simulação coletiva nas PME com a participação de costureiras.

Fonte: Dados da pesquisa

Entre dirigentes de uma mesma PME, a simulação coletiva, que dá forma à visão compartilhada para o lançamento de um novo produto, pode ocorrer como ilustra a passagem a seguir da entrevista com um confeccionista.

\footnotetext{
A morada de nossos planos é nossa cabeça. Eles surgem da conversa do dia-a-dia, às vezes fora da empresa, na casa um do outro, às vezes num passeio, nas viagens feitas para o exterior, nos almoços... Nas lojas, damos uma olhada [nos produtos à venda] $\mathrm{e}$ começamos a imaginar muitas possibilidades... O mundo vira, as coisas mudam [em nossa imaginação]. [Nas lojas, chegamos a nos dizer] "vamos comprar isto agora [como artigo que inspirou uma ideia], é a tendência, vai acontecer... poxa, tem a ver com um mercado que podemos atacar [produzindo novas roupas]...". Então, fazemos isto, trocamos ideias... A gente também procura envolver os nossos clientes [na troca de ideias] dizendo a eles "olha, o que vocês acham? a gente está pensando em fazer isso...". Alguns, quando gostam, podem dizer "poxa, eu topo, vamos fazer, eu tenho mercado [para revender]". Então, é uma conversa franca e muito pessoal. Não tem cartilha para isto. Somos muito práticos. (Dirigente de PME confeccionista de Santa Catarina)
}

Como se vê, a simulação coletiva, que ocorre pelo diálogo e pela interação intensa entre membros de uma organização, pode também contar com a colaboração de atores externos (clientes, por exemplo). Contudo, quando se trata de algo que pode ter um impacto 
significativo sobre os negócios, ela se submete à preponderância dos dirigentes da PME, que fazem questão de conduzi-la.

A simulação coletiva como processo de aprendizagem antecipada (que ocorre antes de se realizar a ideia que está sob apreciação) é mais explícita e consciente do que a simulação mental individual. Pelo que se constatou, a simulação coletiva começa frequentemente quando um ator submete suas hipóteses de solução para uma situação-problema à apreciação daqueles de quem ele respeita a opinião. Não raro, o ator que inicia o processo está interessado em testar ou legitimar iniciativas que ele pensa em empreender. Mas, geralmente, ele está aberto para considerar outras possibilidades que são sugeridas a ele ou que chamam a sua atenção durante uma troca de ideias. Para que o processo possa ter início, os indivíduos participantes devem ter uma percepção compartilhada da situação-problema. Em geral, a pessoa que inicia o processo tende a começar pela explicação de qual é a situação-problema em questão e quais são suas características. Isto se aplica principalmente quando as pessoas consultadas nada conhecem sobre a situação-problema a ser tratada.

No processo de simulação coletiva, a intersubjetividade emerge graças às interações entre diferentes pessoas. Essas interações possibilitam que a aprendizagem dessas pessoas extrapole a esfera das percepções e do pensamento individuais e tornem coletivos conhecimentos, ideias, noções e até mesmo competências. A eficiência na busca de soluções adequadas por meio da simulação coletiva tende a aumentar à medida que esses elementos compartilhados são coerentes com a realidade dos atores envolvidos e da PME em questão.

\subsection{Conversa estratégica}

Como destacado no modelo das relações entre níveis sistêmicos na PME (Esquema 1), a interação entre os dirigentes no seio da equipe de direção é determinante para as PME. Um tipo específico de interação entre eles tem sido negligenciado nos estudos das PME, apesar de ser o definidor de questões capitais para as PME: a conversa estratégica. 


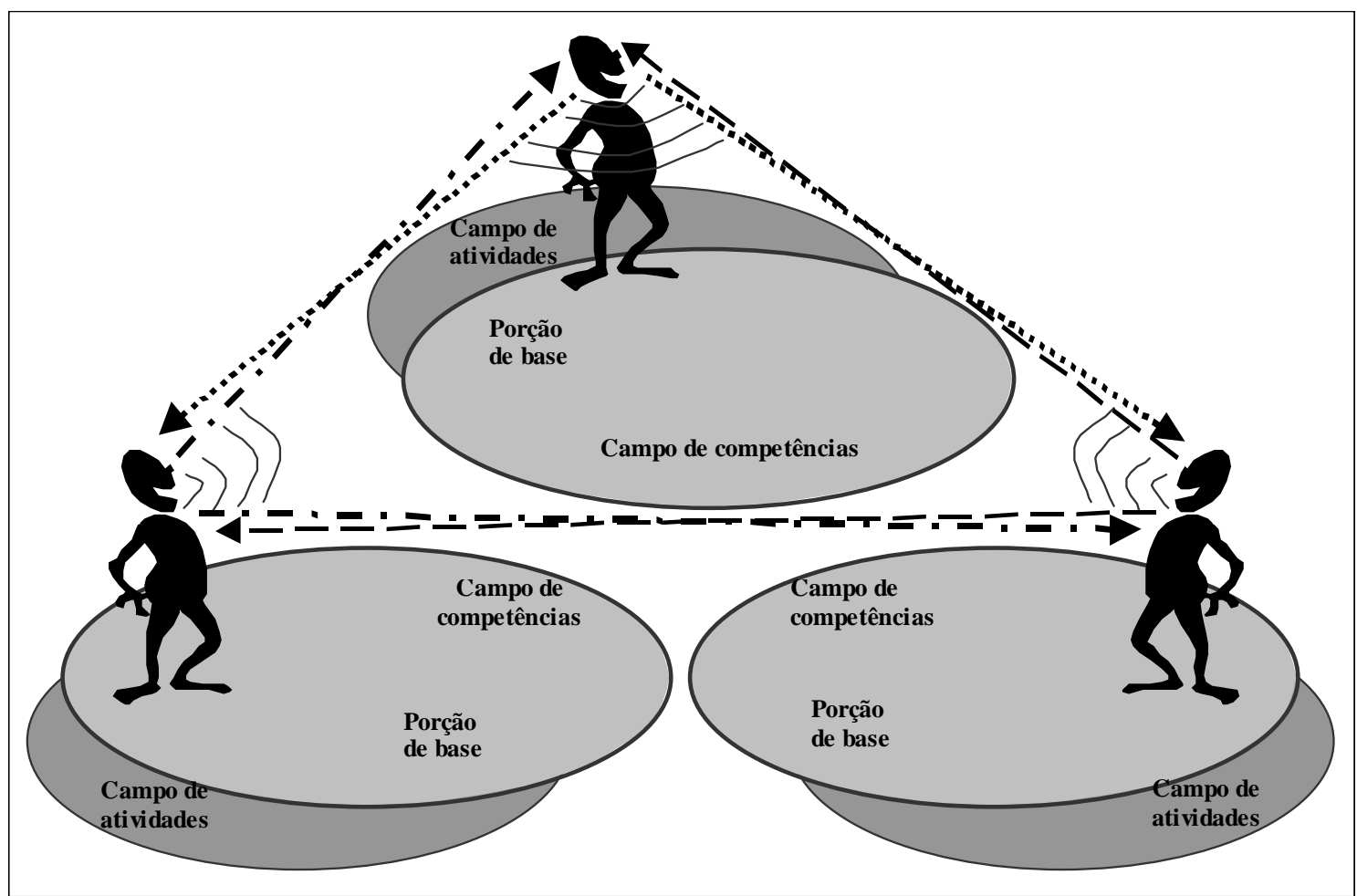

Figura 2: Esquema 2 - Conversa estratégica segundo os campos de atividades e de competências Fonte: Elaborado pelos autores do artigo

Por conversa estratégica, entende-se aqui uma manifestação das relações entre duas ou mais pessoas pela qual uma pode comunicar a outra suas ideias, opiniões, visão e imagens no que diz respeito a questões estratégicas de uma dada organização (LIMA, 2004, 2007). Ela pode ser o meio de realização de uma simulação coletiva, mas apenas quando esta se refere a questões estratégicas. Por tornar possível, entre diferentes atores, a transmissão de elementos da subjetividade relativos a questões estratégicas, ela constitui um dos principais processos que levam ao estabelecimento dos itens de orientação estratégica (missão, visão e objetivos) que se tornam compartilhados pelos dirigentes e que eles buscam compartilhar com os demais membros da PME.

O Esquema 2 representa a conversa estratégica com o exemplo de uma equipe de direção de três dirigentes. Contudo as considerações feitas a partir desse exemplo podem ser transpostas, com alguns ajustes apenas, para a situação de equipes de direção de outros tamanhos na amostra de pesquisa. A análise de dados revelou a importância da conversa estratégica, principalmente em trechos de entrevista como os seguintes:

Jogando uma partida de golfe, em agosto de 1993, eu disse a eles [aos sócios potenciais]: "Este é o momento de criar nossa empresa de biotecnologia. Deveríamos agrupar nossas empresas e nossos projetos porque já tenho financiadores em minha rede de relações. Vocês têm suas empresas e nós temos um 
projeto; colocamos tudo junto e fundamos Thera!" Houve então uma espécie de junção de pessoas de culturas diferentes que se conheciam relativamente pouco. (André de Villers - Theratechnologies - Canadá)

Nessa citação, André de Villers, um dos co-dirigentes fundadores de Theratechnologies, descreve um momento que destaca a importância da conversa estratégica com seus sócios potenciais a fim de realizarem sua visão compartilhada de criação da PME. Ao final, ele indica algumas informações que ajudam a explicar os grandes conflitos ocorridos na equipe de direção nos primeiros anos da empresa.

\footnotetext{
Nós [os diretores] sentamos regularmente para conversar. Conversamos sobre como a empresa está indo bem, para planejar, etc. Devemos tomar as decisões mais importantes juntos, visto que somos sócios. [...] Ele cuida da parte do trabalho dele e eu da minha. Este é o caso dos investimentos. Quando eles são ligados à produção, como sou responsável por esta área, sou eu quem melhor sabe o que é necessário (quando se fala de equipamentos, contratação de pessoal...). A gente sempre troca ideias; sempre dialogamos quando temos que tomar decisões importantes. (Entrevistado: o mesmo dirigente de PME confeccionista de Santa Catarina citado anteriormente)
}

Com essa citação, é possível reforçar a importância da conversa estratégica. O dirigente destaca algo que se repetiu em todos os casos estudados com relação à conversa estratégica: o respeito que um dirigente tem pelo campo de atividades e pelo campo de competências do outro. Assim, a participação de cada dirigente no processo de conversa estratégica é, em grande parte, determinada por seu campo de atividades e por seu campo de competências. Isso é ilustrado pelo Esquema 2.

O campo de atividades de um indivíduo em uma organização é o campo de trabalho na organização que a ele foi atribuído pela diretoria. Esse tipo de atribuição gera expectativas quanto ao papel de cada indivíduo. Assim, espera-se que quem é incumbido de dirigir as atividades de marketing se ocupe, por exemplo, das pesquisas de mercado. Contudo não se espera que essa pessoa se dedique a problemas de finanças.

O campo de competências de um indivíduo agrupa os elementos que lhe conferem seu poder de transformação de sua realidade segundo sua vontade e/ou seus projetos. Esses elementos são ligados a suas capacidades, habilidades e conhecimentos, além de serem influenciados, entre outras coisas, por sua vivência (que inclui suas experiências passadas), sua formação, sua história familiar e sua capacidade de aprendizagem. Em geral, os indivíduos desenvolvem seu campo de competências pelo aprendizado ao longo de sua existência.

A análise dos dados revelou que, na conversa estratégica, cada dirigente contribui para 
o processo baseado principalmente na porção do campo de competências que sustenta mais diretamente seu campo de atividades. No Esquema 2, essa porção é chamada de "porção de base". Nesse sentido, a complementaridade dos dirigentes quanto a seu campo de atividades e a seu campo de competências é fundamental para a qualidade das decisões que eles tomam coletivamente. Os dados revelaram que a complementaridade é especialmente importante para assegurar a coerência dessas decisões com a realidade das PME estudadas. Por exemplo, se a equipe de direção não tem um dirigente com competências suficientes para the auxiliar a cobrir as necessidades das atividades de marketing da empresa, os aspectos da visão compartilhada relativos ao dimensionamento e à caracterização da clientela-alvo, entre outras coisas, podem ser pouco realistas. Esse tipo de limitação pode gerar grandes prejuízos a uma PME.

Não só a conversa estratégica, mas também as decisões tomadas ao longo de seu processo estão sob forte influência da maneira de ser dos dirigentes. Uma passagem da história da PME brasileira WK Sistemas oferece um exemplo eloquente da manifestação dessa influência. Ela trata da mudança da visão compartilhada pelos dirigentes associada ao abandono da prestação de serviços de informática para dar início à produção de softwares padronizados a serem vendidos pelo correio. Werner Keske, fundador da empresa, descreveu assim esta passagem:

Eu tinha um sonho... Quando eu me casei com Maria Ignês [co-dirigente] em 1984, eu lhe disse: "Meu sonho é vender um produto pelo correio... um software ou algo assim que não exija que eu tenha contato pessoal com os compradores..." - para evitar que eu me incomodasse com essas coisas. Minha timidez foi o fator mais relevante para determinar esta preferência pelas vendas pelo correio, mas a experiência que eu tinha tido com meus cursos pelo correio também influenciou. [...] E nós fizemos assim.

A maneira de ser, a visão individual (ou elementos de visão individual) e as experiências passadas de Werner influenciaram sua conversa estratégica com Maria Ignês, desempenhando um papel determinante para a formação dos novos elementos de visão compartilhados pelos dois co-dirigentes.

\section{CONCLUSÃO}

Este artigo trata de elementos relacionados às PME por vezes negligenciados pelos 
pesquisadores em Administração e dificilmente considerados adequadamente nas atividades de formação e de serviço de apoio à gestão das PME. São eles: características das relações entre os membros das PME; a gestão realizada por dirigentes que compõem uma equipe de direção; as influências das relações internas às PME sobre os processos de gestão estratégica; o papel da simulação coletiva como processo de aprendizagem antecipada útil às empresas; a conversa estratégica.

Algumas recomendações úteis para a melhoria das práticas de gestão nas PME podem ser extraídas do presente estudo, reforçando diferentes sugestões já elencadas por Lima, (2007):

- A qualidade da simulação coletiva, da conversa estratégica, da complementaridade e das relações tem um impacto considerável sobre o desenvolvimento das PME; portanto, é recomendável que os dirigentes de PME despendam esforços para que esses itens se aproximem da excelência, o que pode incluir a busca de aperfeiçoamento em programas de formação e de apoio dirigidos à administração de PME;

- Nas PME, faz-se necessário estar atento à qualidade e à quantidade do conteúdo das conversas estratégicas, visto que ele é a "matéria-prima" de muitas decisões estratégicas;

- Aos membros das PME, principalmente aos dirigentes, é aconselhável estar atentos ao perfil e ao potencial de contribuição de cada pessoa da equipe de direção, bem como a suas habilidades humanas; se, por um lado, a capacidade de manter relações adequadas é importante para a qualidade do trabalho de um dirigente, por outro, suas competências e as atividades a ele atribuídas devem contribuir efetivamente para a complementaridade da equipe de direção e para cobrir as necessidades da empresa;

- Isto implica que é aconselhável que os dirigentes estejam continuamente aperfeiçoando suas competências, sua complementaridade e suas habilidades humanas; nessa questão, os formadores e os agentes de apoio têm um papel relevante a desempenhar.

Quanto às sugestões para estudos futuros, há de se destacar que todos os temas elencados no início desta conclusão ainda carecem de mais pesquisas, em razão da natureza exploratória do presente estudo. A exploração de temas como o papel dos membros não dirigentes no processo de gestão estratégica das PME, pouco explorado neste artigo, poderia gerar importantes contribuições em futuras pesquisas. 
Dada a possibilidade de aprofundamento e detalhamento oferecida pelo método etnográfico de pesquisa, e de recursos, como a observação participante, ele também teria muito a contribuir no estudo dos temas aqui propostos. Ele pode dar conta adequadamente de diferentes processos de interação e de aprendizagem organizacional e de grupos, assim como de particularidades culturais ou outras do contexto de cada PME a ser estudada.

\section{Referências}

ARGYRIS, C.; SCHÖN, D. Organizational Learning: a Theory of Action Perspective. Reading: Addison Wesley, 1978.

BARNARD, C. I. The functions of the executive. Cambridge: Harvard University Press, 1938.

BEEBY, M.; BOOTH, C. Networks and Inter-organizational Learning: A Critical Review. The Learning Organization, v. 7, n. 2, p. 75-88, 2000.

EISENHARDT, K. M. Building theories from case study research. Academy of Management Review, Briarcliff Manor, v. 14, n. 4, p. 522-550, 1989.

FILION, L. J. The strategy of successful entrepreneurs in small business: vision, relationships and anticipatory learning. 1988. Tese de doutorado, University of Lancaster, Inglaterra, 1988.

FILION, L. J. Vision and Relations: Elements for a Entrepreneurial Metamodel. Proceedings of the $10^{\text {th }}$ Annual Babson Entrepreneurship Research Conference. In: CHURCHIL, N. C. et al. (Eds.) Frontiers of Entrepreneurship Research. Wellesley: Center for Entrepreneurial Studies, p. 57-71, 1990.

FIOL, M. C. Consensus, Diversity and Learning in Organizations. Organization Science, v. 5, n. 3, p. 403-420, 1994.

FIOL, M. C.; LYLES, M. Organizational Learning. Academy of Management Review, v. 10, p. 803-813, 1985.

GIOIA, D. A.; CHITTIPEDDI, K. Sensemaking and Sensegiving in Strategic Change Initiation. Strategic Management Journal, v. 12, n. 6, p. 433-448, 1991.

GIROUX, N.; TAYLOR, J. Le changement par la conversation stratégique. In: NOËL, A.; VÉRY, P., WISSLER, M. (Eds.). Perspectives en management stratégique. Paris: Economica, 1995. Tome III.

HAFSI, T. Du management au métamanagement: les subtilités du concept de stratégie. Gestion, février, p. 6-14, 1985.

HUBER, G. P. Organizational Learning: The Contributing Processes and the Litteratures. 
Organization Science, v. 2, n. 1, p. 88-115, 1991.

JENNINGS, P.; GRAHAM, B. The Performance and Competitive Advantage of Small Firms: a Management Perspective. International Small Business Journal, v. 15, n. 2, p. 63-75, 1997.

KIM, D. The Link between Individual Learning and Organisational Learning. Sloan Management Review, v. 35, n. 1, p. 37-50, 1993.

LIMA, E. Équipe de direction, vision partagée et apprentissage dans le management stratégique de PME. 2004. 381f. Tese (Doutorado em Administração - Programa conjunto de Ph.D.), HEC Montreal, Montreal, 2004. Disponível em:

<http://home.furb.br/edmilsonlima>. Acesso em: 7 jan. 2007.

LIMA, E. La gestion stratégique de PME face au monde évolutif des affaires: une approche d'apprentissage systémique. In: CONGRÈS INTERNATIONAL FRANCOPHONE EN ENTREPRENEURIAT ET PME, 6, Montreal (Canadá), 2002, Actes du congrès... Montreal, AIREPME, 2002. 1 CD-ROM. Disponível em:

<http://neumann.hec.ca/airepme/actes_2002.html >. Acesso em: 21 fev. 2007.

LIMA, E. Visão Compartilhada, Equipe de Direção e Gestão Estratégica de Pequenas e Médias Empresas: Um Estudo Multi-Caso e Internacional. Revista de Negócios, v. 12, n. 4, p. 15-30, 2007. Disponível em: 〈http://proxy.furb.br/ojs/index.php/rn/issue/view/109>. Acesso em: 16 set. 2008.

LIMA, E.; ZOSCHKE, A. C. K. Relações dos Dirigentes e Gestão Estratégica de Pequenas e Médias Empresas. RAI - Revista de Administração e Inovação, v. 4, p. 150-164, 2007. Disponível em: <http://www.revista-rai.inf.br/ojs-2.1.1/index.php/rai/issue/view/20>. Acesso em: 16 set. 2008.

LUNDBERG, C. C. Learning in and by Organizations: Three Conceptual Issues.

International Journal of Organizational Analysis, v. 3, p. 10-23, 1995.

MILES, M. B.; HUBERMAN, A. M. Qualitative data analysis: an expanded sourcebook. 2. ed. Thousand Oaks: Sage, 1994.

MITROFF, I. Stakeholders of the Organizational Mind. San Francisco: Jossey Bass, 1983.

PETTIGREW, A. M. The Character and Significance of Strategy Process Research. Strategic Management Journal, v. 13, p. 5-16, 1992.

ROBBINS, S. R., DUNCAN, R. B. The Role of the CEO and Top Management in the Creation and Implementation of Strategic Vision. In: HAMBRICK, D. C. (Ed.). The Executive Effect: Concepts and Methods for Studying Top Managers. London: Jai Press, p. 205-233, 1988.

TOMPKINS, T. C. Role of Diffusion in Collective Learning. International Journal of Organizational Analysis, v. 3, p. 69-85, 1995. 